\title{
Breakfast skipping is associated with differences in meal patterns, macronutrient intakes and overweight among pre-school children
}

\author{
Lise Dubois*, Manon Girard, Monique Potvin Kent, Anna Farmer and \\ Fabiola Tatone-Tokuda \\ Institute of Population Health, University of Ottawa, 1 Stewart Street, Ottawa, Ontario, Canada, K1N 6N5
}

Submitted 8 May 2007: Accepted 5 January 2008: First published online 18 March 2008

\begin{abstract}
Objectives: To examine the association between skipping breakfast, daily energy, macronutrients and food intakes, and BMI in pre-school children.

Design: A cross-sectional study using information on children's food consumption and measured height and weight. Energy and macronutrient intakes of the children were derived from parent/day-care attendant's responses to $24 \mathrm{~h}$ recall interviews and eating behaviour questionnaires.

Setting: Data obtained from a representative sample ( $n$ 2103) of children born in Quebec (Canada) in 1998.

Subjects: One thousand five hundred and forty-nine children, with a mean age of 49 (SD 3·12) months.

Results: Ten per cent of children ate breakfast on fewer than 7 days per week. This behaviour was associated with a lower diet quality and concentrated energy intakes through higher protein intakes at lunch and the consumption of snacks higher in energy and carbohydrate in the afternoon and evening; yet total daily energy intakes were not significantly different from those of pre-school children who ate breakfast every day. Breakfast skippers' mean BMI increased as intake of energy, carbohydrates or servings of grain products increased; however, this was not the case for breakfast eaters. When Cole's cut-off for overweight/obesity was used, overweight/obesity in breakfast skippers was related to the dinner-time consumption of approximately $3000 \mathrm{~kJ}(700 \mathrm{kcal})$ or more for energy intake, approximately $100 \mathrm{~g}$ or more of carbohydrates, or approximately 3 servings or more of grain products.

Conclusions: Eating breakfast every day is associated with having a healthy body weight, likely due to a more even distribution of energy intake across meals throughout the day.
\end{abstract}

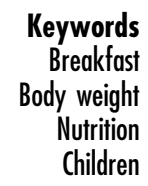

Keywords dy weight Nutrition Children
The prevalence of overweight and obesity among children has increased markedly around the globe ${ }^{(1-4)}$. In Canada, $26 \%$ of 2-17-year-olds were classified as overweight or obese in $2004^{(4)}$. Furthermore, overweight and obesity in childhood has been shown to track into adulthood $^{(5)}$, having significant impacts on overall psychosocial health $^{(6)}$ and predisposing individuals to many causes of morbidity and mortality including diabetes, CVD and hypertension ${ }^{(7,8)}$.

Although causal mechanisms of childhood obesity remain unclear, it is well established that dietary factors play an important role in regulating an overall energy balance, thereby influencing body weight ${ }^{(9)}$. Breakfast eating is one aspect of diet proposed to play a role in the maintenance of a healthy body weight. The authors have reported elsewhere that $9 \cdot 8 \%$ of pre-school children from the present study's population in Quebec (Canada) ate breakfast on fewer than 7 days per week and that overweight was positively associated with this behaviour ${ }^{(10)}$. However, other studies show conflicting results, with some revealing a positive association between breakfast skipping and overweight in populations of school children ${ }^{(11,12)}$ and adolescents ${ }^{(13-16)}$, while other studies found no significant relationship between breakfast skipping and increased $\mathrm{BMI}^{(17,18)}$. In fact, a recent review suggested that the results remain inconclusive ${ }^{(19)}$. Furthermore, this association has not been extensively researched in pre-school populations.

One possible mechanism mediating an association between breakfast skipping and overweight is differences 
in meal patterns and total daily nutrient and energy intakes between individuals who skip breakfast and individuals who eat breakfast every day. Certain studies find support for such differences, indicating that 'breakfast eaters' tend to have higher overall energy intakes than 'breakfast skippers', suggesting that the latter do not make up for these differences at other meals during the day ${ }^{(20,21)}$. Skipping breakfast has also been linked to poorer nutritional habits ${ }^{(22,23)}$. One study showed that children who skipped breakfast consumed fewer grain, fruit and milk products than breakfast eaters ${ }^{(24)}$. Other findings showed that children who skipped breakfast consumed a greater amount of energy and protein at lunch than their peers who ate breakfast ${ }^{(25)}$, while yet other studies suggest that breakfast skipping is associated with increased snacking and larger meal portions for the rest of the day ${ }^{(26)}$. Evidence for supporting the relationship between nutritional adequacy and breakfast eating is moderately strong; however, again, these associations have not been well examined in a pre-school population. Additionally, more research is needed to examine how these associations relate to the development of overweight and obesity in pre-school children.

With reports indicating a 5\% decline in breakfast consumption for pre-school children from 1965 levels in the $\mathrm{USA}^{(16)}$ and similar rates of breakfast skipping in the $\mathrm{UK}^{(27)}$, it is important to properly examine how breakfast eating is associated with regulating healthy dietary habits and maintaining a healthy body weight. For this reason, the present study examined the association between breakfast skipping and daily energy and nutrient intakes, and how these are associated with overall BMI in a population-based sample of pre-school children. It was hypothesized that, after controlling for important covariates, pre-school children who ate breakfast on fewer than 7 days per week would also be found to have a lower diet quality and a higher prevalence of overweight and obesity in comparison with pre-school children who ate breakfast every day.

\section{Methods}

The present study used data from the Longitudinal Study of Child Development in Quebec (1998-2012) (LSCDQ), conducted by Santé Québec, a division of the Institut de la Statistique du Québec (ISQ) in Canada ${ }^{(28,29)}$. The LSCDQ followed a representative sample ( $n$ 2103) of children born in 1998 in the province of Quebec (total population over 7 million, with approximately 70000 newborns per year). To ensure geographic representation and minimize seasonality effects, children born throughout the year in each public health geographic area of the province were randomly selected. Twins and children with major diseases or handicaps at birth were excluded from the study. Children and their parents were first seen at 5 months (adjusted for gestational age) and subsequently at one-year intervals. Each testing point involved standardized, questionnaire-based, face-to-face interviews with the person deemed most knowledgeable of the child, generally the mother.

The analyses presented herein are based on the fifth data collection. Children's mean age was 49 (SD 3.12) months with a range from 44 to 56 months. Of the 2103 infants at the first data collection point, 1944 remained at 4 years in 2002. Of this group, 1549 respondents volunteered to have their child take part in the nutrition component of the study. To ensure that data were longitudinally representative of infants born in 1998, data were weighted by a factor based on the inverse of the selection probability, the probability of non-response and the post-stratification and attrition rates ${ }^{(30)}$. Preliminary analyses indicated that these 1549 children participating in the nutrition survey were representative of the sameaged children in the population. Statistical analyses were based on 1520 pre-school children ( $98 \%$ of the sample), all individuals with no missing values for any of the studied variables. Over half (51\%) of the children were boys, while $49 \%$ were girls. With-and-without analyses were conducted to assess the impact of missing data. Given that missing observations did not have a significant impact on the results, they were excluded from the analyses.

Children's height and weight were measured twice by a trained nutritionist following a standardized protocol; these measures were used to derive children's BMI (calculated as weight $(\mathrm{kg}) /[\text { height }(\mathrm{m})]^{2}$ ). Overweight was defined as: (i) having a BMI at or above the 95th percentile on the sex- and age-specific US Centers for Disease Control and Prevention (CDC) growth charts (at 4.5 years, a BMI cut-off of approximately $18 \cdot 1 \mathrm{~kg} / \mathrm{m}^{2}$ for girls and $17 \cdot 8 \mathrm{~kg} / \mathrm{m}^{2}$ for boys) ${ }^{(31)}$; and (ii) according to Cole's criteria, which provides age- and sex-specific cutoff points from 2 to 18 years for overweight and obesity (at 4.5 years, a BMI cut-off of $17 \cdot 19 \mathrm{~kg} / \mathrm{m}^{2}$ for girls and $17 \cdot 47 \mathrm{~kg} / \mathrm{m}^{2}$ for boys) ${ }^{(32)}$.

\section{Dietary methodology}

The dietary assessment included an eating behaviour questionnaire and a $24 \mathrm{~h}$ dietary recall interview. The $24 \mathrm{~h}$ recall instrument was previously used in the nutrition survey of the Health and Social Survey of Québec Children and Adolescents, 1999. Pre-test of the ISQ $24 \mathrm{~h}$ recall available resulted in changes in the appearance of the instrument; however the content remained the same. All questionnaires and associated technical documents may be accessed through the ISQ website (http://www. jesuisjeserai.stat.gouv.qc.ca/default_an.htm).

Breakfast eating behaviour was measured by a standardized questionnaire ${ }^{(33)}$ and pre-tested in a sample of children not included in the present cohort ${ }^{(34)}$. Parents were asked: 'Does your child eat breakfast in the morning?' Responses included: (1) yes, every morning; (2) regularly 
but not every day; (3) only on occasion; and (4) never. Children who ate breakfast on fewer than 7 days per week (categories 2 to 4) were classified as 'breakfast skippers', while 'breakfast eaters' included children who ate breakfast every morning (category 1). Responses for the breakfast eating behaviour question were compared with the $24 \mathrm{~h}$ recall. In the $24 \mathrm{~h}$ recall, breakfast was defined as the first food eaten as a meal between the hours of 06.00 and 09.00 and by the mother's evaluation (for each mentioned food, the mother was asked by the interviewer to indicate if it was part of a meal or a snack). Meal times are generally stable in Canada; breakfast covers generally the food eaten between 06.00 and 09.00 hours, lunch between 11.00 and 13.00 hours and dinner between 17.00 and 19.00 hours. For $2 \%$ of the children, mothers said that children were eating breakfast every day but mentioned no breakfast items in the $24 \mathrm{~h}$ recall.

Energy, macronutrients, food consumption levels and meal patterns were derived from one $24 \mathrm{~h}$ recall interview administered in the home by a trained nutritionist. Mothers were asked to indicate foods (e.g. type, quantity, recipes) eaten during the $24 \mathrm{~h}$ period preceding the interview. All foods and beverages consumed by the child within the last $24 \mathrm{~h}$ were recorded by the nutritionist. Volume food models were used for determining food portion sizes and food labels were verified for nutrition information. A second $24 \mathrm{~h}$ recall, administered to half ( $n$ 696) the sample approximately $7 \mathrm{~d}$ after the first, allowed for adjustment of recall data for random intrachild variability to ensure representativeness of usual food consumption ${ }^{(35)}$. All analyses were conducted with adjusted data and the results are based on usual food consumptions.

For inconsistent reports between the breakfast eating behaviour questionnaire and the $24 \mathrm{~h}$ dietary recall, the second $24 \mathrm{~h}$ dietary recall, available for $50 \%$ of the sample, was used. Except for one case, children who had no breakfast in the first $24 \mathrm{~h}$ recall had no breakfast in the second $24 \mathrm{~h}$ recall.

The $24 \mathrm{~h}$ recalls obtained for the dietary assessments are considered reasonably accurate for providing group mean estimates of children's intakes while being less burdensome and invasive than food records ${ }^{(36)}$. For children attending day care, nutritionists queried day-care administrative staff regarding the child's food intake (e.g. time, meal, quantity) for the same $24 \mathrm{~h}$ period. For most of the day-care centres, a double sampling procedure was used which involved having day centre staff reserve sample meals, including beverages, the child consumed on the day of interview. The $24 \mathrm{~h}$ recalls were administered evenly across all days in the week. Energy and macronutrient consumption, along with the servings of foods for each meal and for each child, were evaluated according to the Canadian Nutrient File $2001^{(37)}$ and the US Department of Agriculture recipe file ${ }^{(38)}$ which calculates usual consumption of foods in accordance with
Canada's Food Guide to Healthy Eating ${ }^{(39)}$. Dietary data collected were managed using a validated nutrient analysis software package from Micro Gesta (Quebec, Canada; version 73) developed specifically for Canadian nutritional studies (www.microgesta.com). Final consumption and serving estimates were adjusted to minimize within-child variability $^{(34)}$. More details on the study instruments and methodology can be found on the LSCDQ website (http:// www.jesuisjeserai.stat.gouv.qc.ca).

Meal patterns were categorized into breakfast, lunch (including brunch), dinner, morning snacks (including before breakfast snacks), afternoon snacks and evening snacks. For purposes of the analyses, meals were also grouped into two time periods: (i) foods eaten up to and including lunch (including breakfast, brunch, morning snacks and lunch, covering the period between 06.00 and 13.00 hours); and (ii) foods eaten after lunch (including afternoon snacks, dinner and evening snacks, covering the period after 13.00 hours). Total food consumption from meals and snacks was also computed.

\section{Level of physical activity}

Each child's level of physical activity was determined through the mother's response to the question: 'In your opinion, is your child's level of physical activity less than or more than children of the same age and same sex?' Responses included: (1) much higher; (2) slightly higher; (3) equal; (4) slightly less; (5) much less than; (6) do not know; and (7) refused. The responses 'do not know' and 'refused' were coded as missing values.

\section{Statistical analyses}

Statistical analyses were conducted using the SAS statistical software package version 8.2 (SAS Institute, Cary, NC, USA). Weighted data, adjusted for within-child variability, were used in the analysis, and the significance level was set at 5\%. Energy, macronutrients and food servings were analysed as continuous variables and were square-roottransformed whenever normality was not achieved. Given that children's sex and mother's level of education were considered potential confounders, they were included in the analyses ${ }^{(20,22)}$. Odds ratios estimates, including confidence intervals, were determined through logistic regression analyses. Adjusted means were calculated by one-way ANOVA. The list of covariates included in the ANOVA model is noted in the table footnotes. These covariates were selected in correspondence with the literature to ensure proper adjustment for potential confounders (e.g. children's sex) to the main variables of interest.

\section{Results}

\section{Characteristics of the population}

Approximately $8.8 \%$ of children in the cohort were overweight or obese according to the 2000 CDC growth 
charts $^{(31)}$ (age- and sex-specific curves), while $14 \cdot 3 \%$ of the children were classified as overweight or obese when Cole's criteria were used ${ }^{(32)}$. Almost half (47\%) of the children had one overweight or obese parent and 15.5\% had two. Only $14.4 \%$ of children were from single parenting households. Ten per cent of children were from households with an annual income below \$CAN 20000. Over two-thirds of children were in day care $35 \%$ at home day care, $34.2 \%$ in day-care centre ${ }^{(10)}$. The majority of respondents (91\%) completed the French questionnaires. Further details regarding the characteristics of the population have been described elsewhere ${ }^{(10,34)}$.

\section{Energy and macronutrient analyses}

Ten per cent of children ate breakfast on fewer than 7 days per week, being classified as breakfast skippers. Table 1 compares the adjusted means of energy and macronutrient intakes from meals and snacks for breakfast skippers and daily breakfast eaters. On a daily basis, breakfast skippers consumed a lower amount of protein (in grams) and less energy from protein than did breakfast eaters. Breakfast skippers also consumed less energy at breakfast (when they had one) but more energy at lunch time and during afternoon and evening snacks in comparison with breakfast eaters. They also consumed fewer carbohydrates (total) at breakfast and at their morning snack (percentage of energy). More carbohydrates (total) were consumed in their afternoon and evening snacks and, in terms of percentage of energy intake, more carbohydrates were also consumed at dinner. Breakfast skippers also consumed less fat (total) at breakfast and less energy from fat at lunch time than regular breakfast eaters. Lastly, breakfast skippers ate less protein (total) at breakfast but more during their lunch and morning and afternoon snacks.

In terms of energy intake, breakfast skippers consumed less energy and less of each macronutrient (total) from meals, and more energy and more of each macronutrient (total) from snacks than did breakfast eaters. Breakfast skippers also consumed less energy and less of each macronutrient (total) in the pre-lunch period (up to and including lunch), and they consumed more energy and more carbohydrates (total and percentage of energy) in the post-lunch period (data not shown).

\section{Food group serving analyses}

Table 2 compares adjusted means of servings for different food groups consumed at meals and snacks for breakfast skipping and breakfast eating pre-school children. Table 3 describes serving sizes, weight (in grams) and energy values of some common foods in Canada ${ }^{(40)}$. In comparison with breakfast eaters, breakfast skippers consumed a lower mean number of servings from vegetables, grain products and milk products (Table 2). They consumed fewer servings of fruits at breakfast but more at lunch and dinner; fewer servings of vegetables at

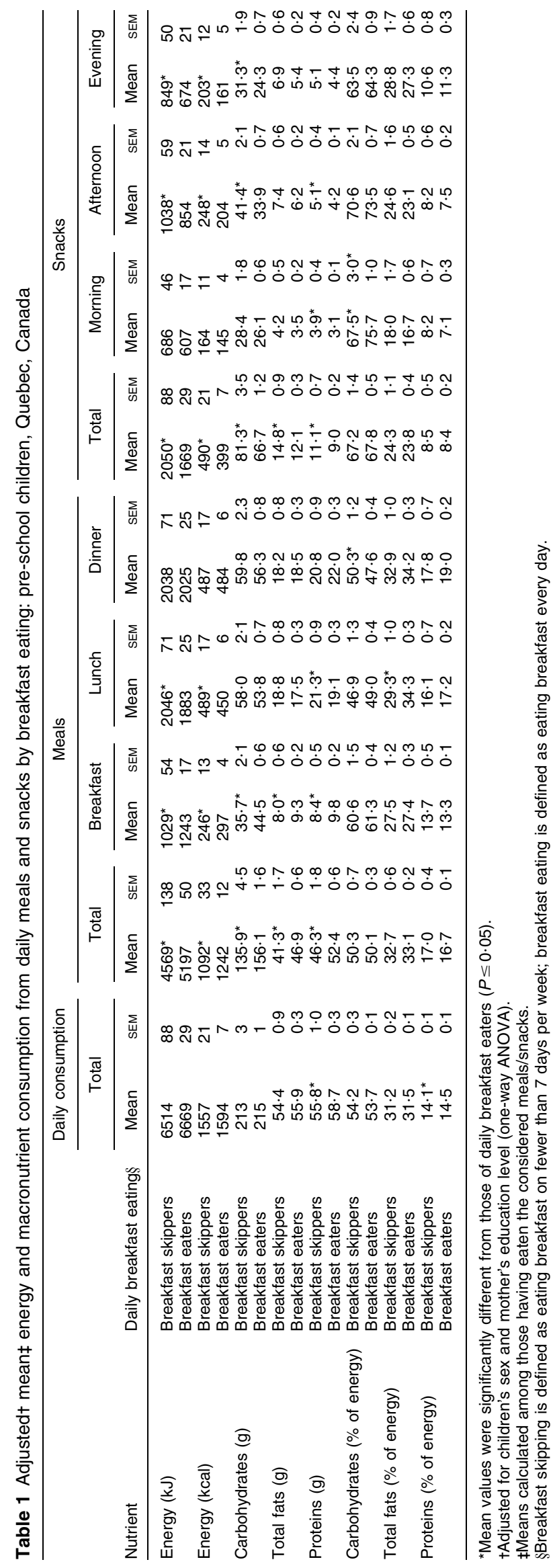


breakfast and more during the evening snack; fewer servings of grain products at breakfast but more at lunch and in the afternoon snack; fewer milk products at dinner but more at the morning snack; and, finally, breakfast skippers consumed more meat and alternatives at lunch time. Globally, breakfast skippers consumed less grain and milk products from meals and more from snacks compared with breakfast eaters. They also consumed fewer servings of grain and milk products in the morning, and more servings of fruit after lunch (data not shown).

\section{Breakfast skipping, energy and macronutrient intakes, and overweight}

In order to examine the association between breakfast skipping and overweight (Table 4), a multivariate analysis was conducted. Results showed that the adjusted odds of being overweight at 4 years among pre-school children was double for breakfast skippers compared with those who ate breakfast every day (model 1). When energy consumption was included in the analysis (model 2), breakfast skipping remained significantly associated with being overweight and this relationship was strengthened. Furthermore, for every $418 \mathrm{~kJ}$ ( $100 \mathrm{kcal})$ increase in energy, the adjusted odds of being overweight was $1 \cdot 22$ (95\% CI 1·14, 1·31). When macronutrients or food groups were considered in a model, breakfast skipping and carbohydrate intake (model 3), and breakfast skipping and servings of grain products (model 4), were both associated with overweight, indicating that carbohydrate intake or intake of grain products may play an important role in the association between breakfast skipping and overweight in pre-school children. In model 3, the adjusted odds of being overweight for breakfast skippers was $2 \cdot 27$ (95\% CI $1.33,3 \cdot 88)$, while for every $10 \mathrm{~g}$ of carbohydrate intake the adjusted odds of being overweight was $1.13(95 \%$ CI $1 \cdot 07,1 \cdot 20)$. In model 4 , the adjusted odds of being overweight for breakfast skippers was $2 \cdot 50$ (95\% CI $1 \cdot 45,4 \cdot 31$ ), and for each added serving of grain products, the adjusted odds of being overweight was $2 \cdot 11(95 \%$ CI $1 \cdot 69,2 \cdot 64)$.

Further analyses were conducted to determine how energy and macronutrient consumption were related to BMI, while taking into account meal and snack patterns. From this analysis it was observed that dinner time was the period where differences in energy and macronutrient intakes between breakfast skippers and breakfast eaters were most strongly related to BMI. Figure 1 illustrates that intake of energy, carbohydrates and grain products were positively associated with mean BMI for breakfast skippers. More specifically, it was observed that the BMI of breakfast skippers increased as the intake of energy, carbohydrates or servings of grain products increased; however, this was not the case for breakfast eaters. When Cole's cut-off for overweight/obesity was used (BMI at $4 \cdot 5$ years of $17 \cdot 19 \mathrm{~kg} / \mathrm{m}^{2}$ for girls and $17 \cdot 47 \mathrm{~kg} / \mathrm{m}^{2}$ for boys $)^{(32)}$, overweight/obesity in breakfast skippers was 
Table 3 Serving sizes, weight and energy values of some common foods in Canadat

\begin{tabular}{|c|c|c|c|c|}
\hline Food & Serving size & Weight $(g)$ & Energy (kJ) & Energy (kcal) \\
\hline \multicolumn{5}{|l|}{ Bread, cereal and other grain products } \\
\hline Bagel $(10 \mathrm{~cm}$ diameter) & 1 & 89 & 1025 & 245 \\
\hline Bread, whole wheat, commercial & 1 slice & 28 & 293 & 70 \\
\hline Bread, pita, white $(16.5 \mathrm{~cm}$ diameter) & 1 & 60 & 690 & 165 \\
\hline English muffin, plain & 1 muffin & 52 & 556 & 133 \\
\hline Oatmeal, quick & $175 \mathrm{ml}$ & 146 & 414 & 99 \\
\hline Corn Flakes & $250 \mathrm{ml}$ & 26 & 423 & 101 \\
\hline Cheerios, General Mills ${ }^{\mathrm{TM}}$ & $250 \mathrm{ml}$ & 24 & 410 & 98 \\
\hline Shreddies, Post ${ }^{\mathrm{TM}}$ & $175 \mathrm{ml}$ & 38 & 586 & 140 \\
\hline Rice Krispies, Kellogg's ${ }^{T M}$ & $250 \mathrm{ml}$ & 29 & 460 & 110 \\
\hline Spaghetti, cooked & $250 \mathrm{ml}$ & 148 & 874 & 209 \\
\hline Rice, white, long-grain, cooked & $250 \mathrm{ml}$ & 185 & 883 & 211 \\
\hline \multicolumn{5}{|l|}{ Fruit } \\
\hline Apples, raw, with skin (7 cm diameter) & 1 apple & 138 & 343 & 82 \\
\hline Bananas, raw & 1 medium & 115 & 439 & 105 \\
\hline Grapes, raw & 10 grapes & 50 & 151 & 36 \\
\hline Oranges, raw & 1 fruit & 311 & 259 & 62 \\
\hline Apple juice, canned & $250 \mathrm{ml}$ & 262 & 515 & 123 \\
\hline Orange juice, canned & $250 \mathrm{ml}$ & 263 & 464 & 111 \\
\hline \multicolumn{5}{|l|}{ Vegetables } \\
\hline Broccoli, cooked & $125 \mathrm{ml}$ & 97 & 113 & 27 \\
\hline Carrots, baby raw & 10 carrots & 100 & 159 & 38 \\
\hline Peas, green, cooked & $125 \mathrm{ml}$ & 85 & 276 & 66 \\
\hline Potatoes, peeled, cooked $(6 \cdot 3 \mathrm{~cm}$ diameter $)$ & 1 potato & 150 & 540 & 129 \\
\hline Tomato sauce, canned & $125 \mathrm{ml}$ & 39 & 678 & 162 \\
\hline Tomatoes, raw (6.6 cm diameter) & 1 tomato & 123 & 109 & 26 \\
\hline \multicolumn{5}{|l|}{ Milk and milk products } \\
\hline Milk, $2 \%$ milk fat & $250 \mathrm{ml}$ & 258 & 536 & 128 \\
\hline Yoghurt, fruit bottom, 1-2\% milk fat & $250 \mathrm{ml}$ & 175 & 741 & 177 \\
\hline Cheese $(5 \mathrm{~cm} \times 2 \mathrm{~cm} \times 0.5 \mathrm{~cm})$ & 4 slices & 52 & 883 & 211 \\
\hline Cottage cheese, $2 \%$ milk fat & $125 \mathrm{ml}$ & 119 & 448 & 107 \\
\hline \multicolumn{5}{|l|}{ Meat and meat alternatives } \\
\hline Egg, cooked & $1 \mathrm{egg}$ & 50 & 326 & 78 \\
\hline Tuna, light canned in water & $125 \mathrm{ml}$ & 79 & 385 & 92 \\
\hline Beef, ground, lean, cooked & 1 patty & 70 & 728 & 174 \\
\hline Chicken, drumstick, cooked & 1 drumstick & 49 & 310 & 74 \\
\hline Beans, baked, canned & $250 \mathrm{ml}$ & 267 & 1243 & 297 \\
\hline Tofu, firm $(4.5 \mathrm{~cm} \times 4 \mathrm{~cm} \times 4 \mathrm{~cm})$ & 1 piece & 80 & 485 & 116 \\
\hline Peanut butter, natural & $30 \mathrm{ml}$ & 32 & 774 & 185 \\
\hline
\end{tabular}

tSource: Nutrient Value of Some Common Foods ${ }^{(40)}$. Serving sizes listed are for children over 6 years to adults; serving sizes suggested for children under 6 years old are approximately half the amounts given.

related to the dinner-time consumption of approximately $3000 \mathrm{~kJ}(700 \mathrm{kcal})$ or more for energy intake, approximately $100 \mathrm{~g}$ or more of carbohydrates, or approximately 3 servings or more of grain products.

\section{Discussion}

Breakfast skipping among young children is a concern given this meal provides a good source of essential nutrients and energy. One-tenth of pre-school children in the present population ate breakfast on fewer than 7 days per week, and pre-school children who skipped breakfast were significantly more likely to be classified as overweight or obese ${ }^{(10)}$. Few studies to date have examined whether the association between breakfast skipping and overweight/obesity in pre-school children is related to differences in the meal patterns, energy and macronutrients consumed by those who skip breakfast compared with those who eat breakfast every day.
The results of the present study indicate that pre-school children who ate breakfast every day generally had more servings of vegetables, grain and milk products throughout the day in comparison with pre-school children who regularly or occasionally skipped breakfast; this suggests that pre-school children who skip breakfast have a lower diet quality. This finding is in accordance with other research in children and adolescents, demonstrating that eating breakfast is associated with more healthful food choices and higher diet quality ${ }^{(21,41)}$.

Although breakfast skippers were found to have lower diet quality, total daily energy intakes were comparable to those of pre-school children who ate breakfast every day, revealing that energy intake missed from skipping breakfast was compensated through foods consumed later in the day. Specifically, pre-school children who skipped breakfast had significantly higher energy intakes at evening snacks than pre-school children who ate breakfast every day. These results correspond with findings in adolescents demonstrating an association between 
Table 4 Adjustedt odds ratios and confidence intervals for breakfast skippers and overweightł by daily consumption of energy, macronutrients and food categories: pre-school children, Quebec, Canada

\begin{tabular}{|c|c|}
\hline & $\begin{array}{l}\text { Overweight } \\
\text { children }\end{array}$ \\
\hline & OR $(95 \% \mathrm{Cl})$ \\
\hline \multicolumn{2}{|l|}{ Model 1: Breakfast eating only } \\
\hline Breakfast eaters $\$ \|$ & 1.00 \\
\hline Breakfast skippers $\S$ & $2 \cdot 00(1 \cdot 20,3 \cdot 35)^{\star}$ \\
\hline \multicolumn{2}{|l|}{ Model 2: Breakfast eating and energy intake } \\
\hline Breakfast eaters $\S \|$ & $1 \cdot 00$ \\
\hline Breakfast skippers§ & $2 \cdot 27(1 \cdot 34,3 \cdot 87)^{\star}$ \\
\hline Energy intake (per $418.4 \mathrm{~kJ} / 100 \mathrm{kcal})$ & $1 \cdot 22(1 \cdot 14,1 \cdot 31)^{\star}$ \\
\hline \multicolumn{2}{|l|}{$\begin{array}{l}\text { Model 3: Breakfast eating and macronutrient } \\
\text { intake }\end{array}$} \\
\hline Breakfast eaters $\S \|$ & $1 \cdot 00$ \\
\hline ippers\$ & $2 \cdot 27(1 \cdot 33,3 \cdot 88)^{\star}$ \\
\hline Carbohydrates (per $10 \mathrm{~g}$ ) & $1 \cdot 13(1 \cdot 07,1 \cdot 20)^{*}$ \\
\hline Total fats $(\mathrm{g})$ & $1.01(0.99,1.04)$ \\
\hline Proteins $(\mathrm{g})$ & $1.01(0.98,1.03)$ \\
\hline \multicolumn{2}{|l|}{ Model 4: Breakfast eating and food groups } \\
\hline Breakfast eaters $\S \|$ & $1 \cdot 00$ \\
\hline Breakfast skippers $\S$ & $2 \cdot 50(1.45,4 \cdot 31)^{\star}$ \\
\hline Vegetables and fruits (no. of servings) & $1.06(0.94,1 \cdot 21)$ \\
\hline Grain products (no. of servings) & $2 \cdot 11(1 \cdot 69,2 \cdot 64)^{\star}$ \\
\hline Milk products (no. of servings) & $1.09(0.83,1.42)$ \\
\hline Meat and alternatives (no. of servings) & $1.17(0.83,1.64)$ \\
\hline
\end{tabular}

*Odds significantly different compared with the reference category ( $P \leq 0.05$, logistic regression analysis).

tAdjusted for children's sex, birth weight, mother's immigrant status, mother's education level, number of parents overweight/obese, mother's smoking status, inactivity index and all included variables in the current model. Models 3 and 4 are also adjusted for energy.

$\ddagger$ Children with BMI at or above the 95th percentile on the US CDC Growth curves (age- and sex-specific curves) ${ }^{(31)}$.

$\S$ Breakfast eating is defined eating breakfast every day; breakfast skipping is defined as eating breakfast on fewer than 7 days per week.

$\|$ Breakfast eaters comprise the reference category.

breakfast skipping and increased energy intakes from snacks ${ }^{(23)}$. However, one study in 10-year-old children contrasts the present study's findings pertaining to total energy intake, reporting that children who skipped breakfast had lower overall energy intakes than children who ate breakfast ${ }^{(25)}$.

The present study also revealed differences in the macronutrient composition of snacks and overall diets of pre-school children who skipped breakfast compared with those who ate breakfast every day. Breakfast skippers' snacks contained more energy, with larger servings of grain, milk products, carbohydrates, total fats and proteins. However, on a daily basis, pre-school children who skipped breakfast consumed significantly less protein and less energy from protein in comparison with pre-school children who ate breakfast every day. Total daily carbohydrate intakes and total fat intakes were not found to differ significantly between breakfast skippers and breakfast eaters. We reported in an earlier publication that children in this cohort also consumed similar types of grain products, which were almost exclusively refined grain products (22\% of grain products) and few were whole-grain products $(2 \% \text { of grain products })^{(34)}$. Although Nicklas
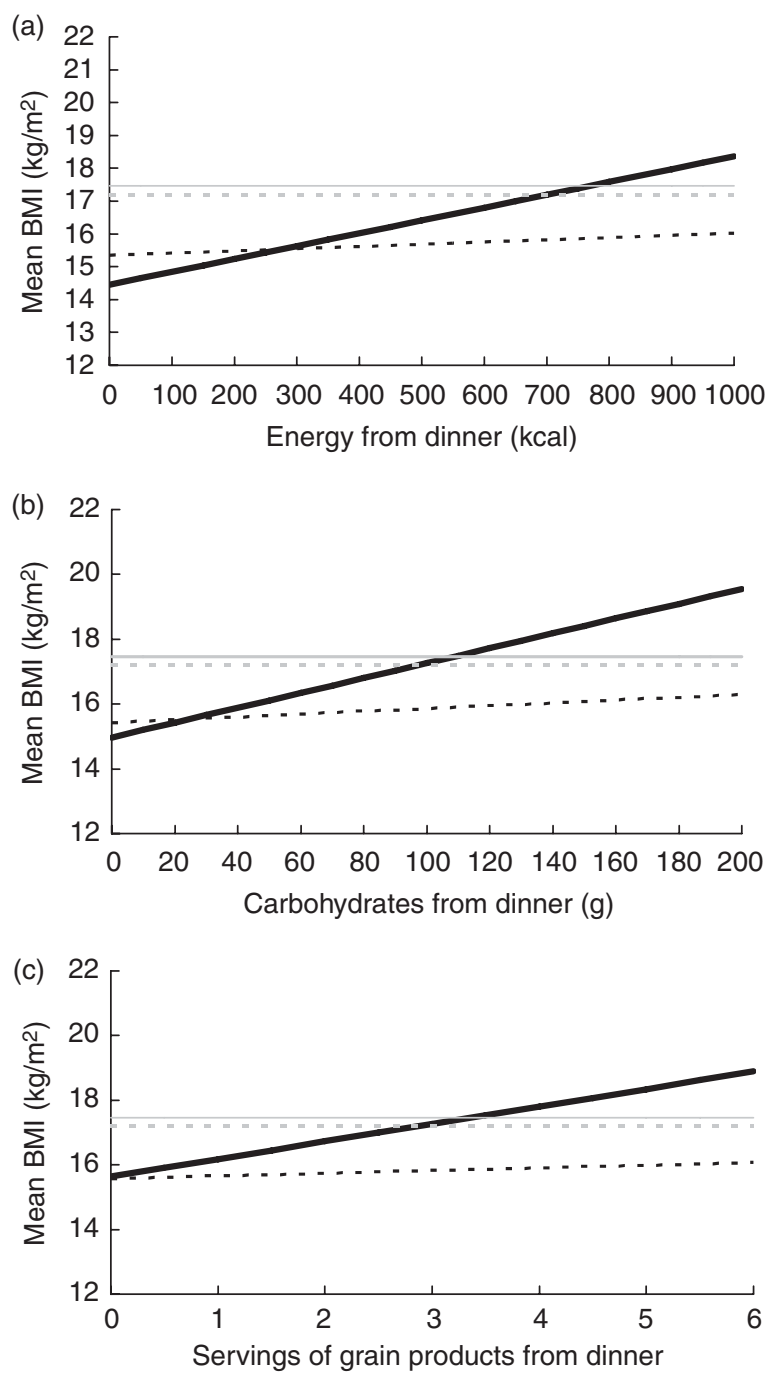

Fig. 1 Adjusted mean BMI (weight/height ${ }^{2}$ ) and (a) daily energy from dinner, (b) carbohydrates from dinner and (c) grain servings from dinner for breakfast eaters (- -) and breakfast skippers (_) among pre-school children, Quebec, Canada. BMI adjusted for children's sex, birth weight, number of parents overweight/obese, inactivity index and energy; additionally for carbohydrates, total fats and proteins in (b) and for vegetables and fruits, grain products, milk products and meat and alternatives in (c). Breakfast eating is defined as eating breakfast every day; breakfast skipping is defined as eating breakfast on fewer than 7 days per week. Also included on the plots are Cole's overweight/obese cut-offs for girls (- - ) and boys (-); a child who has a BMI above these lines is considered to be overweight or obese. Children who skip breakfast have a higher risk - and sooner - of being considered as overweight/obese by Cole's cut-off than children who eat breakfast every day. For example, a breakfast skipper will be reaching Cole's cut-off when his energy consumption is around $3140 \mathrm{~kJ}(750 \mathrm{kcal})$ while a breakfast eater may reach the same target after eating more than $4184 \mathrm{~kJ}(1000 \mathrm{kcal})$. To convert kcal to kJ, multiply by $4 \cdot 184$.

et $a l^{(25)}$ did not find differences in the snack composition of 10-year-old children and adolescents who skipped or ate breakfast, and found differences in total daily carbohydrate and fat intakes between breakfast skippers and 
breakfast eaters, the association between breakfast skipping and lower total daily protein intake found in the present study is consistent with other research ${ }^{(20,42)}$. Differences in the findings across studies may result from differences in the age groups or populations studied.

A more important observation revealed from the present study was that the higher mean BMI found in breakfast skippers was significantly associated with increases in energy, carbohydrates and grain products consumed particularly at the dinner meal; yet this association was not observed for pre-school children who ate breakfast every day. This finding is a relevant one as it implies that the association between breakfast eating behaviours and overweight/obesity in young children may occur through possible interactions between meal patterns, timing of meals and the quantity of carbohydrates consumed in a meal. Several biological pathways may be proposed to explain this observation.

The first theory proposes a potential effect of meal frequency on energy balance. It is not known whether the effects on metabolism of eating regularly are independent of, or mediated by, energy intakes ${ }^{(43)}$. A review of studies examining this relationship reported that, although not all studies found a significant association, of the studies that observed significant results an inverse relationship was reported between meal frequency and body weight ${ }^{(43)}$. However, no association was observed in other reports ${ }^{(44)}$. Again, divergence in the results obtained across studies possibly arises from the differences in age and general makeup of the various populations examined ${ }^{(45)}$. Also, differences in findings among studies may be due to a variety of definitions used for meal patterns ${ }^{(44)}$.

Another theory suggests a link between overweight and eating late in the day. In fact, Bellisle et al. ${ }^{(26)}$ observed that obese and overweight children consumed more energy at the dinner meal than non-overweight children. Indeed, the results of the present study also indicate that breakfast skippers made up energy differences with higher energy intakes at snacks later in the day compared with breakfast eaters, particularly for the late evening snack. Although the directionality of the association cannot be determined from the present findings, it is possible that breakfast eating may be a simple strategy to help reduce energy intakes later in the day, when a child is less likely to be active and expend the energy consumed; this in turn may reduce the child's propensity to gain weight.

A third hypothesis suggests that the glycaemic index of food consumed may also influence body weight ${ }^{(46,47)}$. However, the association between overweight and the glycaemic effect of foods among children is poorly understood. It is thought that different changes in glucose and/or insulin levels in response to carbohydrate intake may have subsequent effects on food intake or the promotion of overweight and obesity ${ }^{(48)}$. Observations from the present study indicate that a carbohydrate load beyond $100 \mathrm{~g}$ at the dinner meal was associated with a greater likelihood of being classified as overweight among breakfast skippers but not among breakfast eaters. It is not known whether the interaction of increased BMI and carbohydrates is due to the quality of carbohydrates ingested or to an altered response to carbohydrates arising from skipped meals ${ }^{(49)}$. Given that this finding raises many issues related to the macronutrient composition of meals, further research is warranted to disentangle the effects of different types of carbohydrates and meal frequency on body weight among pre-school children.

Finally, the increased prevalence of overweight among breakfast skippers may be argued to result from differences in patterns of energy expenditure between preschool children who skipped breakfast compared with those who ate breakfast every day. In fact, studies in adolescent populations have shown an association between lower levels of physical activity and breakfast skipping ${ }^{(15,50)}$. Although the present study did not have an objective measurement of children's level of physical activity, the mother's perceptions of their child's level of physical activity were assessed. However, the results indicated there was no association between mother's perceptions of their child's level of physical activity and breakfast eating or skipping (data not shown). Moreover, results from the multivariate analysis showed that despite statistical adjustments for sedentary behaviour, breakfast skippers consumed more energy and carbohydrates in the post-lunch period, and were more likely to be classified as overweight in comparison with breakfast eaters. Further research among pre-school children investigating differences in the effects of meals, including frequency and timing of meals, is suggested.

The results of the present study must be considered in the light of certain limitations. First, owing to the crosssectional nature of the data, it is recognized that no causal attributions can be assigned to the associations observed in the present report. Reverse causality remains possible, particularly in regard to the role of energy and food consumption. As breakfast skippers were observed to have higher energy intakes at snacks and the dinner meal, compressing energy intakes later in the day may consequently curb children's appetite for eating breakfast the next morning, further promulgating the cycle. Reverse causality also remains possible if it is the case that parents of children who are overweight intentionally try to restrict various aspects of the child's diet, one being the skipping of breakfast. Additional population-based longitudinal research is required to properly examine whether meal patterns, energy and macronutrient intakes increase pre-school children's likelihood of skipping breakfast, thereby promoting prospective weight gain, or whether parental influences and other underlying biological aspects of being overweight/obese predict an individual's meal patterns (including breakfast skipping) and distribution of energy and macronutrient intakes. 
Second, given the self-reported nature of the data obtained for energy intakes from the $24 \mathrm{~h}$ recall, the effect of energy and macronutrient intakes on the association between breakfast skipping and overweight should be interpreted with caution. Some studies found that snack foods are more commonly under-reported than foods consumed at regular meals ${ }^{(51,52)}$. Another study found an under-reporting of energy intakes among overweight women ${ }^{(53)}$. However, there are no reasons to believe that possible biases in self-reported energy intakes are differential across breakfast eating/skipping groups. For this reason, the results are likely to have underestimated the strength of the true association between breakfast skipping, energy and macronutrient intakes, and BMI.

Despite these limitations, the present study has specific strengths. The large sample size and high response rates allow for high confidence in the study results. Strengths also lie in the representative nature of the sample of singletons born in the province of Quebec (Canada) in 1998. Furthermore, the present findings accounted for several important covariates to the main associations, thus controlling for possible inconsistencies found in the previous literature. Due to these strengths, the present study makes important contributions to the literature and furthers understanding of the association between breakfast skipping and overweight in pre-school children.

\section{Conclusions}

In summary, although the total daily macronutrient composition and energy intakes of breakfast skippers were similar to those of pre-school children who eat breakfast every day, breakfast skippers concentrated their energy intakes through higher protein intakes at lunch and the consumption of snacks higher in energy and carbohydrate in the afternoon and evening. These associations corresponded with a higher prevalence of overweight and obesity in pre-school children who skipped breakfast. Given that breakfast eating was found to be associated with the more even distribution of energy intake throughout the day, it is possible that breakfast eating may play a role in the maintenance of a normal weight status and improved diet quality. Public health messages targeting parents of young children need to emphasize the importance of developing healthy eating patterns at a young age, by promoting regular breakfast eating and healthy snack choices over energy-dense snacks for pre-school children.

\section{Acknowledgements}

All authors have seen and approved this manuscript and have met all requirements for authorship. There have not been any prior or duplicate publications or submissions for publications. No conflicts of interest are declared.
Sources of funding: The research work of L Dubois is supported by the Canada Research Chair Program. The study was partly financed by the Canadian Institute of Health Information, Population Health Initiative, and by the Canadian Institute of Health Research. The analyses were performed using data from the Longitudinal Study of Child Development in Quebec (1998-2002) (LSCDQ), conducted by Santé Québec, a division of the Institut de la Statistique du Québec (ISQ) and funded by the Ministry of Health and Social Services of Québec.

Authorship responsibilities: L.D. is the director of the study (questionnaire development, data analysis, interpretation of the data, etc.). M.G. planned and performed the statistical data analysis. M.P.K., A.F. and F.T.T. contributed to literature review, content analysis and writing of the manuscript.

\section{References}

1. Janssen I, Katzmarzyk PT, Boyce WF, Vereecken C, Muvihill C, Roberts C, Currie C \& Pickett W, The Health Behaviour in School-Aged Children Obesity Working Group (2005) Comparison of overweight and obesity prevalence in school-aged youth from 34 countries and their relationships with physical activity and dietary patterns. Obes Rev 6, 123-132.

2. Ogden CL, Flegal KM, Carroll MD \& Johnson CL (2002) Prevalence and trends in overweight among US schoolchildren and adolescents, 1999-2000. JAMA 288, $1728-1732$.

3. Rennie KI \& Jebb SA (2005) Prevalence of obesity in Great Britain. Obes Rev 6, 11-12.

4. Shields M (2005) Measured obesity: overweight Canadian children and adolescents. In Nutrition: Findings from the Canadian Community Health Survey, issue no. 1. Catalogue no. 82-620-MWE2005001. Ottawa: Statistics Canada.

5. Guo SS, Wu W, Chumlea WC \& Roche AF (2002) Predicting overweight and obesity in adulthood from body mass index values on childhood and adolescence. Am J Clin Nutr 76, 653-658.

6. Kiess W, Galler A, Reich A, Muller G, Kapellen T, Deutscher J, Raile K \& Kratzsch J (2001) Clinical aspects of obesity in childhood and adolescence. Obes Rev 2, 29-36.

7. Kannel WB (1997) Effect of weight on cardiovascular disease. Nutrition 13, 157-158.

8. Visscher TLS \& Seidell JC (2001) The public health impact of obesity. Annu Rev Public Health 22, 355-375.

9. World Health Organization (2004) Obesity: Preventing and Managing the Global Epidemic. Report of a WHO Consultation. Technical Report Series no. 894. Geneva: WHO.

10. Dubois L, Girard M \& Potvin Kent M (2006) Breakfast eating and overweight in a pre-school population: is there a link? Public Health Nutr 9, 436-442.

11. Vignerová J, Bláha P, Roth Z \& Ošancová K (2004) Social inequality and obesity in Czech school children. Econ Hum Biol 2, 107-118.

12. Wolfe WS \& Campbell CC (1993) Food pattern, diet quality, and related characteristics of schoolchildren in New York State. J Am Diet Assoc 93, 1280-1284.

13. Berkey CS, Rockett HRH, Gillman MW, Field AE \& Colditz GA (2003) Longitudinal study of skipping breakfast and weight change in adolescents. Int $J$ Obes Relat Metab Disord 27, 1258-1266. 
14. Dwyer JT, Evans M, Stone EJ, Feldman HA, Lytle L, Hoelscher D, Johnson C, Zive M \& Yang M (2001) Adolescent's eating patterns influence their nutrient intakes. J Am Diet Assoc 101, 798-802.

15. Keski-Rahkonen A, Kaprio J, Rissanen A, Virkkunen M \& Rose RJ (2003) Breakfast skipping and health-compromising behaviors in adolescents and adults. Eur J Clin Nutr $\mathbf{5 7}$, 842-853.

16. Siega-Riz A-M, Popkin B \& Carson $T$ (1998) Trends in breakfast consumption for children in the United States from 1965-1991. Am J Clin Nutr 67, 748S-756S.

17. Abalkhail B \& Shawky S (2002) Prevalence of daily breakfast eating, iron deficiency anaemia and awareness of being anemic among Saudi school students. Int J Food Sci Nutr 53, 519-528.

18. Walker ARP, Walker BF, Jones J \& Ncongwane J (1982) Breakfast habits of adolescents in four South African populations. Am J Clin Nutr 36, 650-656.

19. Rampersaud G, Pereira M, Girard B, Adams J \& Mietzl J (2005) Breakfast habits, nutritional status, body weight and academic performance in children and adolescents. I Am Diet Assoc 105, 743-760.

20. Nicklas TA, Reger C, Myers L \& O’Neil C (2000) Breakfast consumption with and without vitamin-mineral supplement use favorably impacts daily nutrient intake of ninthgrade students. J Adolesc Health 27, 314-321.

21. Skinner JD, Salvetti NN, Ezell JM, Penfield MP \& Costello CA (1985) Appalachian adolescents' eating patterns and nutrient intakes. J Am Diet Assoc 85, 1093-1099.

22. Serra-Majem L, Ribas L, Perez-Rodrigo C, Garcia-Closas R, Pena-Quintana L \& Aranceta J (2002) Determinants of nutrient intake among children and adolescents: results from the enKid study. Ann Nutr Metab 46, Suppl. 1, 31-38.

23. Sjöberg A, Hallberg L, Höglund D \& Hulthén L (2003) Meal pattern, food choice, nutrient intake and lifestyle factors in The Göteborg Adolescence Study. Eur J Clin Nutr 57, 1569-1578.

24. Basiotis PP, Lino M \& Anand RS (1999) Eating breakfast greatly improves school children's diet quality. Family Econ Nutr Rev 12, 81-84.

25. Nicklas TA, O'Neil CE \& Berenson GS (1998) Nutrient contribution of breakfast, secular trends, and the role of ready-to-eat cereals: a review of data from the Bogalusa Heart Study. Am J Clin Nutr 67, Suppl., 757S-763S.

26. Bellisle F, Rolland-Cachera MF, Deheeger M \& GuilloudBataille M (1988) Obesity and food intake in children: evidence for a role of metabolic and/or behavioural daily rhythms. Appetite 11, 111-118.

27. Hackett AF, Gibbon M, Sratton G \& Hamill L (2002) Dietary intake of 9-10-year-old and 11-12-year-old children in Liverpool. Public Health Nutr 5, 449-455.

28. Dubois L, Bédard B, Girard M \& Beauchesne É (2000) Nutrition: Québec Longitudinal Study of Child Development, 1998-2002: 5 Month Old Infants. Québec: Québec Statistical Institute; available at http://www.stat.gouv.qc.ca. publications/sante/rapport_an.htm

29. Dubois L \& Girard M (2002) The Nutrition of Preschool Children: Québec Longitudinal Study of Child Development, 1998-2002. Québec: Québec Statistical Institute; available at http://www.stat.gouv.qc.ca.publications/ sante/rapport_an.htm

30. Cox BG \& Cohen SB (1985) Methodological Issues for Health Care Surveys. New York: Marcel Dekker.

31. National Center for Health Statistics, Centers for Disease Control and Prevention (2000) 2000 CDC Growth Charts: United States. http://www.cdc.gov/growthcharts/

32. Cole TJ, Bellisi C, Flegal KM \& Dietz WH (2000) Establishing a standard definition for child overweight and obesity worldwide: international survey. BMJ 320, 1240-1243.
33. Institut de la statistique du Québec (1999) Enquête sociale et de santé auprès des enfants et des adolescents québécois (Health and Social Survey of Québec Children and Adolescents). Québec: ISQ.

34. Bédard B \& Dubois L (2005) Apports en énergie et en macronutriments. In Enquête de nutrition auprès des enfants québécois de 4 ans, pp. 67-77. Québec: Institut de la Statistique du Québec.

35. Liu K, Stamler J, Dyer A, McKeever J \& McKeever P (1978) Statistical methods to assess and minimize the role of intraindividual variability in obscuring the relationship between dietary lipids and serum cholesterol. J Chronic Dis 31, 399-418.

36. Goran MI (1998) Measurement issues related to studies of childhood obesity: assessment of body composition, body fat distribution, physical activity and food intake. Pediatrics 101, 505-516.

37. Health Canada (2001) Canadian Nutrient File, 2001 version. Ottawa: Health Canada.

38. US Department of Agriculture (1997-1998) NFCS Food Codes (Release 1) linked to 1985 Nutrient Data (Release 2). Accession no. B87-142451. Washington, DC: USDA.

39. Health Canada (2005) Canada's Food Guide to Healthy Eating. Ottawa: Health Canada; available at http://www. hc-sc.gc.ca/fn-an/food-guide-aliment/index_e.html

40. Health Canada (1999) Nutrient Value of Some Common Foods. Ottawa: Canadian Government Publishing; available at http:// www.hc-sc.gc.ca/fn-an/nutrition/fiche-nutri-data/index_e.html

41. Lattimore PJ \& Halford JC (2002) Adolescence and the diet-eating disparity: healthy food choice or risky health behaviour? Br J Health Psychol 8, 451-463.

42. Nicklas TA, Myers L, Reger C, Beech B \& Berenson GS (1998) Impact of breakfast consumption on nutritional adequacy of the diets of young adults in Bogalusa, Louisiana: ethnic and gender contrasts. J Am Diet Assoc 98, 1432-1438.

43. Bellisle F, Mcdevitt R \& Prentice A (1997) Meal frequency and energy balance. Br J Nutr 77, Suppl. 1, S57-S70.

44. Nicklas TA, Morales M, Linares A, Yang SJ, Baranowski T, De Moor C \& Berensen G (2004) Children's meal patterns have changed over a 21-year period: The Bogalusa Heart Study. J Am Diet Assoc 104, 753-761.

45. Nicklas TA, Su-Jau Yang MS, Baranowski T, Zakeri I \& Berenson G (2003) Eating patterns and obesity in children: The Bogalusa Heart Study. Am J Prev Med 25, 9-16.

46. Ludwig DS (2002) The glycemic index: physiological mechanisms relating to obesity, diabetes, and cardiovascular disease. JAMA 287, 2414-2423.

47. Ludwig D, Majzoub J, Al-Zahrani A, Dallal G, Blanco I \& Roberts S (1999) High glycemic index foods, overeating and obesity. Pediatrics 103, e26.

48. Ludwig DS (2000) Dietary glycemic index and obesity. J Nutr 130, 280S-283S.

49. Farshchi H, Taylor M \& Taylor I (2005) Beneficial metabolic effects of regular meal frequency on dietary thermogenesis, insulin sensitivity and fasting lipid profiles in healthy obese women. Am J Clin Nutr 81, 16-24.

50. Cohen B, Evers S, Manske S, Bercovitz K \& Edward HG (2003) Smoking, physical activity and breakfast consumption among secondary school students in a southwestern Ontario community. Can J Public Health 94, 41-44.

51. Krebs-Smith SM, Graubard BI, Kahle LL, Subar AF, Cleveland LE \& Ballard-Barbash R (2000) Low energy reporters vs. others: a comparison of reported food intakes. Eur $J$ Clin Nutr 54, 281-287.

52. Basiotis PP, Lino M \& Dinkins JM (2000) Consumption of food group servings: people's perceptions vs. reality. Nutrition Insight. Washington, DC: USDA Center for Nutrition Policy and Promotion.

53. Hirvonen T, Männiströ S, Roos E \& Pietinen P (1997) Increasing prevalence of underreporting does not necessarily distort dietary surveys. Eur J Clin Nutr 51, 297-301. 